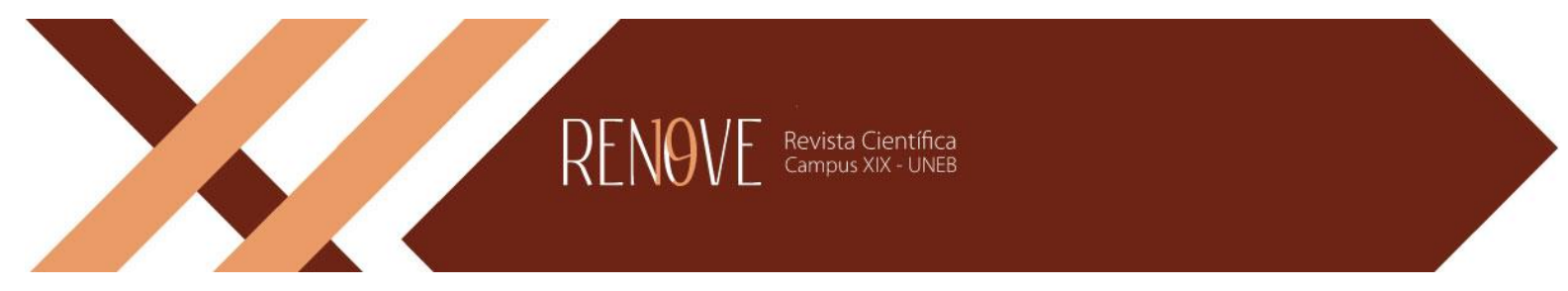

\title{
A REPARAÇÃO POR DANOS EXTRAPATRIMONIAIS NA RELAÇÃO DE TRABALHO E A OFENSA GRAVÍSSIMA
}

\author{
Geórgia Rocha Roma \\ Bacharela em Direito pela Faculdade do Sul da Bahia. \\ Teixeira de Freitas-Bahia/Brasil. \\ E.mail: georgia.rocha.roma@outlook.com \\ Miriam Kelly Teixeira Silva \\ Bacharela em Direito pela Faculdade do Sul da Bahia. Teixeira de Freitas-Bahia/Brasil. \\ Teixeira de Freitas-Bahia/Brasil \\ E.mail: mirian-kelly2011@hotmail.com \\ Gine Alberta Ramos Andrade Kinjyo \\ Mestre em Ciência, Tecnologia e Educação - FVC/ES. Profa. Auxiliar da Faculdade do Sul da Bahia. \\ Teixeira de Freitas-Bahia/Brasil. E.mail: ginekinjyo@gmail.com \\ http://lattes.cnpq.br/7127244982521886
}

\section{Resumo:}

Este estudo tem por premissa, discutir a tarifação do dano extrapatrimonial, uma inovação ao ordenamento jurídico pátrio, trazida pela Reforma Trabalhista (Lei n. 13.467/17). Assim, temse por objetivo, analisar a constitucionalidade do dano extrapatrimonial disposto no artigo 223 $\mathrm{G}$, parágrafo $1^{\circ} \mathrm{da} C L T$, em cotejo com os princípios correlatos à matéria, para fins e discussão acerca do espectro de alcance da parametrização da reparação extrapatrimonial definida como de natureza gravíssima, a partir da avaliação das normas correlatas. A pesquisa aborda a evolução histórica do trabalho, perpassando pelas modalidades de responsabilidade civil do empregador, e por fim, analisa o teor do art. 223-G, $\S 1^{\circ}$, IV, da CLT, sempre à luz da norma constitucional, com vistas a perquirir se o novel artigo, cumpre atender ao disposto nos princípios norma da igualdade, da reparação integral do dano e da dignidade da pessoa humana. A perquirição da pesquisa, centra-se na seguinte problematização: os critérios trazidos pela Reforma Trabalhista para fins de tarifação acerca do quantum da reparação civil à título de dano extrapatrimonial no Direito do Trabalho, são suficientes para quantificar o dano extrapatrimonial? Tem-se por método a pesquisa bibliográfica, através da análise da norma, da construção doutrinária e produção jurisprudencial, com especial, no que tange às decisões dos Tribunais Regionais do Trabalho. Tem-se como referencial teórico, Cairo Júnior (2016), Romar (2017), Tremel e Calcini (2018), Gonçalves (2019), Martinez (2020) dentre outros. Ao final do estudo, os resultados da pesquisa permitem concluir pela inconstitucionalidade do art. 223-G, $\S 1^{\circ}$, IV, da CLT, à luz das reiteradas decisões dos Tribunais Regionais do Trabalho e da doutrina pertinente. $O$ resultado da pesquisa demonstrou que a jurisprudenciais produzidas pelos tribunais trabalhistas, são no sentido de declarar a inconstitucionalidade do artigo 223-G, $\S 1^{\circ}$, da CLT, que trata da tarifação do dano extrapatrimonial, essa também é a posição das autoras.

Palavras-chave: Direito do Trabalho. Princípios Constitucionais. Reforma Trabalhista. Dano extrapatrimonial. Parametrização do Dano Moral. 


\title{
REMEDY FOR OFF-BALANCE SHEET DAMAGES IN THE EMPLOYMENT RELATIONSHIP AND THE SERIUOS OFFENSE
}

\begin{abstract}
:
This study's premise is to discuss the off-balance sheet tariff, an innovation to the national legal system, brought about by the Labor Reform (Law No. 13,467 / 17). Thus, the objective is to analyze the referred legal innovation, in the light of the Federal Constitution of 1988, as well as of the infraconstitutional norm, in comparison with the principles related to the matter. The research addresses the historical evolution of the work, going through the modalities of civil liability of the employer, and finally, it analyzes the content of art. 223-G, § 1, IV, of the CLT, always in the light of the constitutional norm, with a view to ascertaining whether the new article, must comply with the provisions of the norm principles of equality, full reparation of the damage and the dignity of the human person. The investigation of the research, focuses on the following problematization: are the criteria brought by the Labor Reform for pricing purposes regarding the quantum of civil reparation as off-balance sheet damages in Labor Law, sufficient to quantify off-balance sheet damages? Bibliographic research is used as a method, through the analysis of the norm, doctrinal construction and jurisprudential production, with special regard to the decisions of the Regional Labor Courts. The theoretical framework is Cairo Júnior (2016), Romar (2017), Tremel and Calcini (2018), Gonçalves (2019), Martinez (2020), among others. At the end of the study, the results of the research allow us to conclude that art. $223-\mathrm{G}, \S 1^{\circ}, \mathrm{IV}$, of the CLT, in the light of the repeated decisions of the Regional Labor Courts and the pertinent doctrine.
\end{abstract}

Keywords: Labor Law. Constitutional principles. Labor Reform. Off-balance sheet damage. Moral damage pricing.

\section{INTRODUÇÃO}

A configuração dos danos de natureza extrapatrimonial na seara trabalhista, decorre da inobservância dos direitos trabalhistas de valor imaterial, como a vida, a honra, a imagem e a incolumidade física. Contudo, antes da entrada em vigor da Reforma Trabalhista (Lei n. 13.467/17), não existia na Consolidação das Leis do Trabalho (CLT), previsão legal específica que tratasse da responsabilidade pelo dano moral de natureza extrapatrimonial sofrido pelo trabalhador. Assim, as decisões tinham por arcabouço normativo, o Código Civil e demais normas civis, aplicando-se os princípios do direito laboral, com base nos dos critérios da razoabilidade e da proporcionalidade do dano, diante da ação ou omissão praticada, tendo o nexo de causalidade, como elo entre o dano extrapatrimonial e a conduta ofensiva.

A Lei n. 13.467/17, denominada Reforma Trabalhista, inovou em sede da indenização por danos de natureza extrapatrimonial, decorrentes da execução do contrato de trabalho, de modo a inserir na norma trabalhista o novo art. 223-G, que passou a prever os 
critérios a serem considerados para fins de arbitramento da indenização por danos imateriais, bem como, trouxe ainda, a fixação de tetos indenizatórios discriminados a partir do salário recebido pela vítima, o que fora denominado pela doutrinada por "tarifação do dano moral nas relações de trabalho".

O presente estudo, tem por objetivo, analisar a constitucionalidade do dano extrapatrimonial disposto no artigo $223 \mathrm{G}$, parágrafo $1^{\circ}$ da CLT, em cotejo com os princípios correlatos à matéria, para fins e discussão acerca do espectro de alcance da parametrização da reparação extrapatrimonial definida como de natureza gravíssima, a partir da avaliação das normas correlatas, considerando que a análise da legislação pode propor caminhos para a concretização do direito a reparação civil por dano extrapatrimonial. Tem-se portanto, como referencial teórico, Cairo Júnior (2016), Romar (2017), Tremel e Calcini (2018), Gonçalves (2019), Martinez (2020) dentre outros. Ao final do estudo, os resultados da pesquisa permitem concluir pela inconstitucionalidade do art. 223-G, § $1^{\circ}$, IV, da CLT, à luz das reiteradas decisões dos Tribunais Regionais do Trabalho e da doutrina pertinente

O estudo conta com três sessões, sendo que na primeira, traz a origem e evolução histórica do Direito do Trabalho, que teve seu nascimento a partir da primeira Revolução Industrial (século XVIII ao XIX), em decorrência de movimentos sociais que eclodiram em busca de melhorias no âmbito social do trabalho. A segunda, examina as modalidades da Responsabilidade Civil no ordenamento pátrio e os requisitos essenciais para configuração da responsabilização do empregador, quais sejam: o dano, a ação ou omissão, o nexo de causalidade e a culpa. Já a terceira, analisa o modo como os tribunais brasileiros têm abordando a questão do arbitramento da indenização por danos imateriais no Direito do Trabalho, quando da configuração da ofensa de natureza gravíssima. Diante do exposto, entende-se pela relevância do tema, haja vista que os tribunais trabalhistas estão firmando interpretação sobre a matéria.

\section{ORIGEM E EVOLUÇÃO HISTÓRICA DO DIREITO DO TRABALHO}

O Direito é constituído por um sistema de ramos, institutos, princípios e normas que se destinam a disciplinar a vida na sociedade. No caso específico do Direito do Trabalho, é um ramo que tem por objeto, regulamentar a relação de trabalho e emprego. Impossível seria portanto, o estudo da evolução do Direito do Trabalho sem a análise, ainda que sucinta, sobre a evolução do próprio trabalho desde a antiguidade até a contemporaneidade. Na Antiguidade, 
o trabalho apresentava um sentido negativo, sendo visto como um castigo no pensamento clássico grego.

Com o passar do tempo, criou-se o escambo ou atividade de troca que, posteriormente, foi se adaptando para fins de conversão do valor de uso em valor de troca. Assim, a mercadoria substituiu a moeda, com o escopo de prover o seu sustento e produzir riquezas, culminando mais tarde, na valorização do trabalho do homem e no lucro empresarial diante do investimento na produção. A concepção do trabalho na vida do indivíduo é inaugurada quando este percebe que é possível utilizar a mão de obra alheia não apenas para a produção de bens em consumo próprio, mas também como meio de produzir riquezas. Dessa forma, o trabalho torna-se dependente e intrínseco às relações sociais e econômicas ao longo da história.

Já o Direito do Trabalho surge com o advento da primeira Revolução Industrial, a partir do século XVIII ao XIX, sobretudo em decorrência dos movimentos operários, que buscavam a melhoria das condições de trabalho, limitação da jornada de trabalho e proteção ao trabalho da mulher e das crianças. Assim, conforme esclarece, NASCIMENTO (2004, p. 32),

\footnotetext{
O direito do trabalho surgiu como consequência da questão social que foi precedida pela Revolução Industrial do século XVIII e da reação humanista que se propôs a garantir ou preservar a dignidade do ser humano ocupado no trabalho das indústrias, que, com o desenvolvimento da ciência, deram nova fisionomia ao processo de produção de bens na Europa e em outros continentes. A necessidade de dotar a ordem jurídica de uma disciplina para reger as relações individuais e coletivas de trabalho cresceu no envolvimento das "coisas novas" e das "ideias novas", como passamos a mostrar.
}

Com o desenvolvimento do comércio e das atividades urbanas, corroborada pela produção artesanal de bens, vivenciou-se naquele momento, o declínio da sociedade feudal, pois como bem assevera ROMAR (2017, p. 31), sobre os trabalhadores daquele período "muitos deles eram os antigos servos, que tinham algum ofício e até então o praticavam exclusivamente para seus senhores".

Como forma se garantir prerrogativas de cunho comercial e social, os artesãos fundaram associações profissionais, o que deu origem às corporações de ofício, compostas pelos mestres, companheiros e aprendizes. Em 1789, com o advento da Revolução Francesa, prevaleceu a noção de igualdade, liberdade e fraternidade, reconhecendo o direito à liberdade do cidadão, marcando o início do Estado liberal (MARTINS; REIS, 2019).

Com a constituição do Estado liberal, foi criado um novo sistema legislativo protecionista, intervencionista, de maneira que o Estado passou a assumir um papel mais intervencionista, com o fim de impedir a exploração do trabalho. Nesse período, é que 
surgiram os primeiros instrumentos constitucionais de real importância, objetivando o resguardo da garantia de direitos dos trabalhadores.

O Tratado de Versalhes, assinado pela Alemanha e pelos países signatários em 1919, foi um dos primeiros documentos que normatizaram direitos específicos aos trabalhadores, ao garantir que o trabalho não devesse ser considerado apenas como mercadoria. Ademais, o tratado foi responsável pela criação da Organização Internacional do Trabalho - OIT (CAIRO JÚNIOR, 2016). Em suma, os sistemas de proteção do trabalhador advindos da evolução ocorrida após a Revolução Industrial e a evolução histórica do trabalho humano, leva ao nascimento de uma legislação que preceitue condições mínimas de proteção a serem respeitadas pelos empregadores. Um claro exemplo foi a regulamentação do trabalho assalariado, com mecanismos de proteção ao trabalhador, havendo limitação da vontade das partes. Daí surge o Direito do Trabalho, como norma que assegura o interesse geral sobre o parcial, sem deixar de garantir os direitos básicos do trabalhador. Com o passar do tempo, o Estado progrediu de liberal para social, com a intervenção progressiva na ordem econômica e social, em especial, após a $2^{\mathrm{a}}$ guerra mundial.

No que tange ao Brasil, o Direito do Trabalho no Brasil foi segmentada em dois períodos, sendo um período anterior à Revolução de 1930, ou seja, as Constituições Brasileiras anteriores a 1930 (1824 e 1891) e um período posterior à Revolução 1930 (1934, 1937, 1946, 1967), com as respectivas alterações (MARTINS, 2015).

No primeiro período havia ausência de proteção aos trabalhadores. Isso resta comprovado, pelo fato de que as Constituições de 1824 e de 1891, não constarem em seu texto, qualquer previsão, que denotasse possíveis limites ao mercado e possível intervenção estatal nas relações contratuais de trabalho.

A ausência de dispositivos constitucionais sobre o trabalho, nas Constituições do Império (1824) e da $1^{\text {a }}$ República (1891), tem relação com a condição do Brasil como um país escravocrata e sem interesse em regulamentar o trabalho e a mão de obra dos libertos, no pós abolição de 1888, bem como daqueles obreiros que já eram livres nesse tempo. Os trabalhadores da indústria, no início do século XX no Brasil, laboravam em completa condição de exploração.

A partir de 1930, registra-se o início da intervenção do Estado nas relações de trabalho, sendo que as Constituições que se seguiram, passaram a prever em seus textos, os direitos sociais, sobrevindo a proteção do trabalhador como garantia constitucional. Em 1934, surgiu a primeira Constituição que tratou sobre o Direito do Trabalho, com dispositivos que 
versavam sobre garantias trabalhistas, sendo a isonomia salarial, a liberdade dos sindicatos, a proteção ao trabalho da mulher e do adolescente (GARCIA, 2015).

O Direito do Trabalho no Brasil, tem sua gênese a partir da Revolução de 1930, quando o Governo Provisório chefiado por Getúlio Vargas, cria o Ministério do Trabalho, Industria e Comércio, com a regulamentação de medidas legislativas que abriram caminho para a autonomia do Direito do Trabalho no Brasil, de maneira que em 1943, passa a vigorar no país, a Consolidação das Leis do Trabalho, aprovada pelo Decreto-lei $n^{\circ} 5.452$, de 01 de maio de 1943.

O modelo justrabalhista adotado no Brasil, impôs uma constante e permanente intervenção do Estado nas relações de emprego. Tal interferência foi estendida às entidades sindicais e à solução dos litígios porventura surgidos, culminando na adoção do sistema de solução judicial.

A Carta Magna de 1988 é uma Constituição que trouxe importantes avanços de âmbito social, ao consagrar os direitos trabalhistas como autênticos direitos fundamentais. Neste contexto, a sociedade brasileira após a promulgação da Constituição Federal de 1988, compreendeu o alcance das novas regras que valorizam o pleno exercício da cidadania.

Em 2017, com Lei n. ${ }^{\circ}$ 13.467, de 14 de julho de 2017, foi publicada a Reforma Trabalhista, que já adentra o ordenamento jurídico com sérias críticas e divergências doutrinária e jurisprudenciais. A Lei 13.467/2017, dentre outras mudanças legislativas, introduziu a regulamentação da flexibilização das regras do contrato de trabalho, passou a permitir a precarização do labor, instituiu três princípios de proteção ao capital, tais como: a liberdade, a segurança jurídica e a simplificação, além de alterar o texto da CLT, sob o argumento da necessidade da modernização das relações trabalhistas.

\section{RESPONSABILIDADE CIVIL DO EMPREGADOR}

Ao tratar do instituto da responsabilidade civil, GONÇALVES (2019, p. 19), afirma que toda atividade que acarreta prejuízo traz em seu bojo, como fato social, o problema da responsabilidade. Destina-se ela a restaurar o equilíbrio moral e patrimonial provocado pelo autor do dano". Dessa forma, a responsabilidade civil tem por fulcro, restabelecer o equilíbrio violado pelo dano, fonte geradora da responsabilidade pela reparação, ou seja, funda-se na contraprestação e na reparação de dano causado à vítima.

O dano, decorrente da ação ou omissão, associado ao nexo de causalidade e à culpa, constituem-se requisitos essenciais para configuração da responsabilidade civil. No que se 
refere à seara trabalhista CAIRO JÚNIOR (2016, p. 947), é categórico em afirmar que "o dano trabalhista nada mais é do que a diminuição do patrimônio valorado economicamente do seu respetivo titular por conta da ação ou omissão do empregado ou do empregador. É representado pelo lucro cessante ou pelo dano emergente".

A inobservância dos direitos trabalhistas, como a vida, honra, a imagem e a incolumidade física ou psíquica, ensejam a reparação de dano moral nas relações laborais e, por isso, a Justiça do Trabalho é competente para conhecer, processar e julgar demandas dessa natureza, onde se pleiteia a indenização por danos morais decorrentes da relação de trabalho. A competência da Justiça do Trabalho para enfrentamento de tais demandas, tem amparo constitucional, no artigo 114, inciso VI, Constituição Federal de 1988, a saber: "Compete à Justiça do Trabalho processar e julgar: (...) VI - as ações de indenização por dano moral ou patrimonial, decorrentes da relação de trabalho" (BRASIL, 1988).

Uma vez fixada a competência da Justiça do Trabalho para processar e julgar as demandas concernentes à indenização por dano moral ou patrimonial nas relações do trabalho, mister se faz, conceituar esse dano. Para CAIRO JÚNIOR (2016, p. 949), “o dano moral corresponde a um resultado de uma ação ou omissão que implique, de forma necessária, ofensa a um bem não avaliável economicamente".

É sabido que, quando o dano moral origina-se da relação de execução e extinção do contrato de trabalho, pelo empregado ou pelo empregador, caracterizado está, o dano moral trabalhista, haja vista o efeito indireto ou conexo ao contrato de trabalho. Como causadores de dano moral, é possível exemplificar: o desrespeito à intimidade, a vida privada, a honra e a imagem, assim como, a incolumidade física e psíquica.

Nesta senda, para caracterização do dano moral suportado pelo empregado na relação laboral, a ação ou omissão precisa ser causada pelo empregador ou por seus prepostos, se estes exercerem cargo de direção. Conforme preceitua o artigo 932, III, do Código Civil ${ }^{1}$, a empresa responde, também, por omissões e atos praticados por seus diretores, chefes e prepostos.

O Código Civil disciplinou genericamente a responsabilidade extracontratual em seus artigos 186 a 188 e, assim como, nos artigos 927 a 954. Já a responsabilidade contratual, tem previsão nos artigos 389 e s. e 395 e seguintes, não as diferenciando efetivamente. Sobre as especificidades que diferenciam a responsabilidade civil contratual e a extracontratual, para

\footnotetext{
${ }^{1}$ BRASIL, Código Civil. Art. 932. São também responsáveis pela reparação civil: III - o empregador ou comitente, por seus empregados, serviçais e prepostos, no exercício do trabalho que lhes competir, ou em razão dele. Disponível em: < http://www.planalto.gov.br/ccivil_03/leis/2002/110406compilada.htm>. Acesso em 27 de outubro de 2020.
} 
GONÇALVES (2019, p. 45), de maneira didática, assevera que: "Na responsabilidade extracontratual, o agente infringe um dever legal, e, na contratual, descumpre o avençado, tornando se inadimplente".

No que concerne à responsabilidade contratual, disposta nos artigos 389 e s. e 395 do Código Civil (BRASIL, 2002) e seguintes, é possível afirmar que esta derivada de ilícito extracontratual, também chamada de aquiliana. Neste caso, inexiste um acordo prévio entre as partes, bem como não há vínculo jurídico entre a vítima e o causador do dano, quando da prática do ato ilícito, passível de reparação.

Acerca da responsabilidade a contratual, GONÇALVES (2019, p. 46), esclarece que “o devedor só não será condenado a reparar o dano se provar a ocorrência de alguma as excludentes admitidas na lei: culpa exclusiva da vítima, caso fortuito ou força maior. Incumbelhe, pois, o onus probandi ${ }^{2}$ ".

$\mathrm{Na}$ seara trabalhista, a responsabilidade do empregador, causada pela ação ou omissão, que obrigue o dever de indenizar à título de dano moral, tem para parte da doutrina, natureza contratual, já que as normas legais se tornam conexas à relação de trabalho, configurando assim, cláusulas contratuais da relação jurídica.

A indenização por dano moral ou à imagem representa, portanto, direitos não patrimoniais. Por isso, a ofensa ao patrimônio imaterial do trabalhador deve ser ressarcida pelo empregador, por meio de reparação a título de dano moral ou de dano à imagem. A responsabilidade atribuída ao empregador nessas situações, quando da prática de determinadas condutas, diretamente por ele empregador, ou por seus prepostos em desfavor do trabalhador, está relacionada com ato discriminatório, ofensa à intimidade, ofensa à vida privada, ofensa à honra ou ainda, ofensa à imagem.

Neste diapasão, quaisquer atos de discriminação praticados em desfavor do empregado, permite a este, pleitear a reparação, através de uma indenização a título de danos morais. Conforme preceitua o art. $4^{\circ}$, Lei n. $9.029 / 95^{3}$, até mesmo o rompimento da relação de trabalho, fundada em motivo discriminatório. Portanto, além da reparação pelo dano moral, é facultado ao trabalhador optar entre: a) a reintegração no emprego, com ressarcimento integral de todo o período de afastamento, mediante pagamento das remunerações devidas,

${ }^{2}$ Encargo de provar. Expressão que deixa ao acusador o trabalho de provar (a acusação). Disponível em:< https://www.dicionariodelatim.com.br/onus-probandi/>. Acesso em 27 de outubro de 2020.

${ }_{3}^{3}$ BRASIL. Lei n. 9.029/95, $4^{\circ}$, de 13 de abril de 1995. Proíbe a exigência de atestados de gravidez e esterilização, e outras práticas discriminatórias, para efeitos admissionais ou de permanência da relação jurídica de trabalho, e dá outras providências. Disponível em:< http://www.planalto.gov.br/ccivil_03/leis/19029.htm>. Acesso em: 28 de outubro de 2020. 
corrigidas monetariamente e acrescidas de juros legais; ou b) a percepção, em dobro, da remuneração do período de afastamento, corrigida monetariamente e acrescida de juros legais.

No que diz respeito à diferenciação entre a responsabilidade contratual e a extracontratual, é possível vislumbrar alguns aspectos delimitadores. A primeira diferenciação se refere ao ônus da prova, vez que, na responsabilidade extracontratual, a vítima da ação tem o ônus de provar que o fato se deu por culpa do agente. Entretanto, no caso de responsabilidade contratual, basta que a vítima tenha êxito em provar que o contrato não fora cumprido, configurando-se no dever de indenizar por parte do causador do dano. A segunda diferenciação, nas fontes provenientes, vez que a responsabilidade contratual tem seu nascimento na convenção e, por seu turno, a extracontratual deriva da inobservância do dever genérico de não causar dano a ninguém (neminem laedere ${ }^{4}$ ). A terceira diferença, está relacionada à capacidade do agente causador do dano. Já a quarta e última característica diferenciadora, se refere a gradação da culpa.

As duas modalidades de responsabilidade, extracontratual e contratual, emanam da culpa do agente causador do dano, ao passo que a obrigação de indenizar o delito decorre da lei. Esses dois fatores tem como consequência a apuração da responsabilidade. Nessa senda, é a lição de GONÇALVES (2019, p. 48), ao argumentar que: "na responsabilidade delitual, a falta se apuraria de maneira mais rigorosa, enquanto na responsabilidade contratual ela variaria de intensidade de conformidade com os diferentes casos". Portanto, no âmbito da responsabilidade contratual, a culpa obedece a um nível de progressividade, diante dos diferentes casos em que ela é aplicada, em contrapartida na obrigação derivada de um delito, a responsabilidade teria uma alcance maior.

As principais espécies de dano moral são, o dano moral puro, o dano moral físico e estético e o dano moral coletivo. O primeiro deles, o dano moral puro, é representado pela dor subjetiva não mensurável externamente por terceiros. Nesse sentido, explica CAIRO JÚNIOR (2016, p. 949) que: "não há como provar, materialmente, o dano moral puro, pois ele não se exterioriza. Consequentemente, essa espécie de dano não pode ser percebido pelos sentidos humanos."

A espécie de dano pode vir ainda, cumulada com outra modalidade de dano, como por exemplo, dano físico ou dano estético ou ainda, os dois associados. O dano físico incide quando é atingido algum órgão do corpo humano, por meio de lesão corporal ou perturbação funcional. A prova nos casos de dano físico será feita por perícia médica, já no dano estético,

\footnotetext{
${ }^{4}$ Neminem laedere é uma expressão em língua latina que significa, após tradução para a língua portuguesa, "a ninguém ofender". Disponível em: 〈https://pt.wikipedia.org/wiki/Neminem_laedere〉. Acesso em 27 de outubro de 2020 .
} 
dispensa-se essa espécie de prova técnica, pois ocorre alteração das condições do padrão biológico do indivíduo (CAIRO JÚNIOR, 2016).

Frisa-se que, o dano moral e o dano estético representam dois institutos diferentes. Portanto, na ocorrência de dano estético e de dano moral puro, a indenização deverá abarcar essas duas situações, de maneira que na sentença o magistrado deva fazer constar que a indenização se refere ao dano moral puro e ao dano estético. Outrossim, esse entendimento encontra-se na Súmula 387 do STJ, ao dispor sobre a possibilidade de cumulação de indenização por danos morais e estéticos, a saber: "É possível a cumulação das indenizações de dano estético e moral" (Súmula 387 do STJ). ${ }^{5}$ Destaca-se que a tese da natureza jurídica pedagógica do caráter indenizatório da condenação em favor de pessoais jurídicas ou coletivas, é pacificado na jurisprudência pátria, conforme dispõe a Súmula 227 do STJ: “A pessoa jurídica pode sofrer dano moral."

É inafastável, a premissa de que o dano moral é aquele representado pela dor subjetiva não detectável externamente por terceiros, por conta disso não há como provar, materialmente, o dano puro. Já o dano físico consiste naquele provocado a algum órgão do corpo humano do ofendido, podendo ser constatado externamente. Contudo, o dano estético difere dos demais, por modificar o padrão biológico e social de beleza. Por fim, quando a ofensa atinge os direitos e interesses coletivos sem conteúdo econômico, resta configurado o dano moral coletivo.

\section{A REPARAÇÃO DOS DANOS EXTRAPATRIMONIAIS NO DIREITO DO TRABALHO}

Os danos morais atingem o patrimônio imaterial, intangível ou sensível da pessoa humana. Ao enfrentar o tema, de maneira clara e bem didática, esclarece MARTINEZ (2020, p. 275) que "é certo, sim, que, uma vez constatadas tais transgressões, elas conduzem à presunção de dolorosas percepções anímicas como, por exemplo, a perda, o desprestígio, o desalento, a amargura ou a indignidade."

Como pontua o jurista acima mencionado, é certo afirmar que o dano moral decorre da violação dos direitos da personalidade, tais como o nome, à imagem, a privacidade, à honra, à boa fama, à dignidade, entre outros, afetando a esfera psíquico, moral e intelectual dos

${ }^{5}$ STJ, Súmula 387. Disponível em:< https://ww2.stj.jus.br/publicacaoinstitucional/index.php/Sml/article/view/64/3210>. Acesso em: 28 de outubro de 2020.

${ }^{6} \mathrm{STJ}$, Súmula 227. Disponível em:<

https://ww2.stj.jus.br/publicacaoinstitucional/index.php/Sml/article/view/64/3210>. Acesso em: 28 de outubro de 2020 . 
indivíduos. O que provoca na vítima, inúmeras emoções desagradáveis, como dor, vexame, humilhação, angústia, constrangimentos, vergonha, entre outras.

A Lei n. 13.467/2017, trouxe em seu artigo 223-B, a configuração do dano extrapatrimonial, dispondo que: “Art. 223-B. Causa dano de natureza extrapatrimonial a ação ou omissão que ofenda a esfera moral ou existencial da pessoa física ou jurídica, as quais são as titulares exclusivas do direito à reparação" (BRASIL, 2017).

Importante destacar ainda que, a Lei n. 13.467/2017, em seu artigo 223-G, alterou o sistema jurídico trabalhista, ao orientar a conduta dos magistrados, mensurando variáveis para o arbitramento da indenização por dano moral, com os devidos referenciais para o arbitramento.

O primeiro critério é a natureza do bem jurídico tutelado, à exemplo do direito à honra, à igualdade, à liberdade religiosa, à integridade física, todos em seus reflexos imateriais. O segundo critério refere-se à intensidade do sofrimento ou da humilhação, assim, analisa-se a consequência do ato causador do dano moral em relação ao sentimento da vítima. A par disso, é que TREMEL; CALCINI (2018, p. 100), aduzem que:

\footnotetext{
A rigor, a hipótese é de o juiz considerar a intensidade do desconforto ao bem-estar da pessoa, já que da lesão ao bem imaterial nem sempre se pode afirmar que a pessoa passou por um sofrimento ou que foi humilhado. Ao certo, porém, sempre há um certo desconforto ou sensação negativa.
}

Dessa maneira, é possível afirmar que o legislador não avalia o bem jurídico em si lesionado, como por exemplo a honra ou a igualdade, mas sim, a sua consequência no sentimento do indivíduo. Importante salientar que a lesão moral está relacionada aos sentimentos da pessoa, à sua subjetividade, o que ocasiona certa infelicidade, por atingir um sentimento negativo no ser humano.

Por outro lado, o terceiro critério diz respeito a possibilidade de superação física ou psicológica em relação à lesão ao bem jurídico imaterial tutelado, já que o dano imaterial é um prejuízo imposto à qualidade de vida da pessoa, atingindo sua dignidade e qualidade de vida.

O quarto critério se refere aos reflexos pessoais e sociais da ação ou da omissão, levando em consideração as consequências que decorrem da lesão moral. Assim, ainda conforme asseveram TREMEL; CALCINI (2018, p. 104), “Aqui, então, o juiz deve busca verificar se do ato do ofensor se gerou, além do dano moral em si, outras consequências que podem potencializar a ofensa em sua extensão". Quando for violado o direito à honra, por exemplo, se faz necessário aferir os reflexos na vida social da pessoa da vítima. Isso diante dos nefastos efeitos que a violação da honra pode provocar no ânimo do indivíduo. Outrossim, 
pode refletir também, no seu bom nome, sendo estas consequências pessoais e sociais consideradas para fins de arbitramento da indenização.

Em contrapartida, o quinto critério diz respeito à extensão e a duração dos efeitos da ofensa, na medida em que a lesão moral, tanto pode ser superada de forma rápida, quanto pode perdurar por um tempo razoável ou até mesmo ser indefinida a duração dos efeitos da lesão.

O sexto critério se refere às condições em que a ofensa ocorreu, ou o prejuízo moral suportado, cabendo o magistrado avaliar, por exemplo, se a lesão moral foi em decorrência de ato motivado por violenta emoção.

No sétimo critério, é preciso avaliar o grau de dolo ou culpa. O grau de dolo é novidade legislativa. Para TREMEL; CALCINI (2018, p. 107), tal condição se caracteriza "porque nosso legislador, de um modo geral, nunca distinguiu o grau do ato doloso para fins de avaliação do dano causado a outrem". No que diz respeito a culpa, sua análise centra-se na fixação do dano material, conforme parágrafo único do art. 944 do Código Civil, ao dispor que "a indenização mede-se pela extensão do dano. De forma a fazer consta ainda no parágrafo único que: "se houver excessiva desproporção entre a gravidade da culpa e o dano, poderá o juiz reduzir, equitativamente, a indenização" (BRASIL, 2002).

O oitavo critério diz respeito à ocorrência de retratação espontânea por parte do ofensor, ou seja, é avaliada a conduta do ofensor em tentar diminuir o dano, buscando desmentir a ofensa lançada contra a vítima pelo próprio ofensor. $\mathrm{O}$ esforço efetivo para minimizar a ofensa é classificado como outro critério, podendo este ser por meio da retratação espontânea ou pela adoção de outras condutas aptas a minimizar a ofensa moral. Ainda conforme TREMEL; CALCINI (2018, p. 109), um exemplo seria "publicar o desmentido em redes sociais, periódicos, etc.”.

Já o décimo critério diz respeito ao perdão, tácito ou expresso. Sobre isso, TREMEL; CALCINI (2018, p. 110) apontam que "este não é um fator a ser considerando pelo juiz para a fixação da indenização por danos morais, mas, sim, um fator de rejeição do pedido de pagamento desta prestação". Assim, o perdão põe fim à obrigação, por isso é incabível qualquer indenização a título de danos morais.

O décimo primeiro critério é a situação social e econômica das partes envolvidas, referindo-se a condição social e profissional da pessoa, ou seja, o estado civil, a idade, tempo de vida provável, educação, nível cultural, profissão entre outros aspectos. Por fím, o décimo segundo e último critério, diz respeito ao grau de publicidade da ofensa, de maneira a buscar mensurar, o sofrimento da vítima quando a ofensa alcança maior conhecimento público, sendo esta passível de extensão do dano. 
Após analisar os referidos critérios, caberá ao magistrado tentar aferir a personalidade íntima do ofendido com o fulcro de analisar a extensão da lesão, em uma percepção menos subjetiva. Por isso, TREMEL; CALCINI (2018, p. 115), aduzem que,

\footnotetext{
Definidos os critérios para avaliação do dano moral, caberá ao juiz considerar todos eles, no que for pertinente ao caso em julgamento, para efeito de arbitramento da indenização. E a partir dos referidos critérios caberá ao juiz tentar, a partir de um padrão médio, estabelecer o perfil da personalidade íntima do lesionado de modo que se possa arbitrar a extensão da lesão, de forma menos subjetiva quanto possível. Procura-se a partir desses parâmetros "construir" a personalidade da vítima de modo que se possa apurar o sentimento íntimo violado.
}

Imperioso destacar que o juiz deverá estabelecer se a ofensa configura-se como de natureza leve, média, grave ou gravíssima, sendo que para cada uma dessas formas, serão considerados valores específicos, como parâmetro para a condenação do ofensor à título de indenização, variando entre 3 a 50 vezes, o último salário do empregado. Nestes termos, o legislador apontou os fatores a serem observados pelo magistrado trabalhista, quando do julgamento do pedido de reparação por danos morais extrapatrimoniais.

Ao decidir sobre a indenização do dano extrapatrimonial, o magistrado deverá analisar os parâmetros constantes no já mencionado artigo art. 223-G da CLT, de maneira que, ao considerar a ofensa como de natureza gravíssima, conforme o art. 223-G, $\S 1^{o}, I V$, poderá haver uma condenação para o ofensor, no limite de até cinquenta vezes o último salário contratual do ofendido. (BRASIL, 2017).

Configurado o dano moral e caracterizado o nexo causal, existe a consequente obrigação civil de reparação à vítima. Nos termos do que dispõe o art. 223-G, $\S 1^{\circ}$, da CLT, as indenizações serão calculadas com base no salário do empregado, bem como, o magistrado no caso concreto analisará o dano moral estipulado no valor da dignidade humana, considerado atributo da personalidade humana.

É nesse sentido que parte da jurisprudência tem aplicado o referido artigo como tarifação da indenização por dano extrapatrimonial. Conforme pode ser exemplificado, à luz da decisão do Tribunal Regional do Trabalho da $3^{\mathrm{a}}$ Região (processo n. ${ }^{0}$ 001051006.2019.5.03.0129), de relatoria do Desembargador Vitor Salino de Moura Eça, ao definir o quantum indenizatório pela análise do art. 223-G da CLT, em consonância com o princípio da razoabilidade, a saber:

Para fixar o "quantum" indenizatório, o julgador deve se valer da inteligência do art. 223-G da CLT, bem como no princípio da razoabilidade. No caso em apreço, o importe de $\mathrm{R} \$ 2.000,00$ foi fixado com base no que dispõe o artigo 223-G da CLT, bem como afigura-se razoável e suficiente para compensar a violação aos direitos 
do reclamante em razão dos constrangimentos que suportou em face do comportamento ofensivo do representante da ré. ${ }^{7}$

Entretanto, como as indenizações por danos morais são estabelecidas com valores máximos a partir do salário percebido pela vítima, surge a discussão no que tange à suposta inconstitucionalidade do art. 223-G da CLT. Isso, diante de entendimento jurisprudenciais e doutrinários contrários à aplicação desse dispositivo, por entenderem que ele viola os princípios da dignidade da pessoa humana, da reparação integral dos danos extrapatrimoniais e da isonomia, previstos nos artigos $1^{\circ}$, III, e $5^{\circ}$, caput e incisos V e X, da Constituição Federal.

Por isso, quando do estabelecimento da indenização pelo dano moral, deve o magistrado se ater à relação de proporcionalidade entre a violação do direito e a indenização devida. Por seu turno, a Constituição Federal estabelece que o princípio da proporcionalidade deve ser norteador para fins de parametrização da indenização em casos de violação do direito. Por isso, a legislação infraconstitucional precisa ser interpretada à luz da Constituição Federal, o seria critério a justificar a arguição e, conseguinte declaração de inconstitucionalidade de possível legislação de exceção.

É nesse sentido também, a decisão exarada no processo de $\mathrm{n}^{\circ}$. 000051408.2020.5.08.0000, do Egrégio Tribunal Regional do Trabalho da $8^{\mathrm{a}}$ Região, no que se refere ao princípio da proporcionalidade, o TRT da $8^{\text {a }}$ Região, ao decidir que,

\begin{abstract}
Como regra de hermenêutica prevalece a ideia de que a Lei não contém palavras inúteis. A Constituição Federal ao prever, por exemplo, o direito de resposta proporcional ao agravo, além da indenização por dano material, moral ou à imagem, deixa claro que a existência de um liame entre o dano sofrido e a indenização devida. Quanto maior o dano, quanto maior o agravo, maior a indenização, que deve ser aferida no caso concreto, sob a prudente análise do órgão julgador. A Constituição foi expressa ao exigir uma relação de proporcionalidade entre a violação do direito e a indenização devida. Trata-se de norma constitucional originária, cláusula pétrea com máxima densidade normativa, que, como dito alhures, deve irradiar seus efeitos para todos os ramos do Direito. É preciso dizer o óbvio: a legislação infraconstitucional deve ser interpretada à luz da Constituição e não o contrário. Deve ser repudiada toda e qualquer "legislação de exceção".
\end{abstract}

Na supramencionada decisão, o TRF da $8^{\text {a }}$ Região, firmou entendimento conforme o disposto no $\S 1^{\circ}$ do art. 223-G da CLT, ao vincular a indenização por danos morais ao salário percebido pela vítima. Para parte da doutrina, decisões como essa, afrontam o princípio da igualdade, já que os indivíduos que recebem salário menor terão a fixação do dano moral em valor inferior a de outros trabalhadores pessoas que percebem salário maior. Assim, no caso de indenização de um mesmo evento danoso, poderá haver quantificação diferenciada par o

${ }^{7}$ JUSTIÇA DO TRABALHO. TRIBUNAL REGIONAL DO TRABALHO DA $3^{\mathrm{a}}$ REGIÃO. PROCESSO N. ${ }^{\circ}$ 0010510-06.2019.5.03.0129. DESEMBARGADOR VITOR SALINO DE MOURA EÇA. Disponível em:< https://juris.trt3.jus.br/juris/detalhe.htm?conversationId=661>. Acesso em 05 de novembro de 2020. 
mesmo tipo de dano, ao ser considerado apenas quantum do salário da pessoa ofendida. A claramente visto que a fixação de tais tetos, podem sim limitar a atuação do magistrado que, deve ter por critério, decidir à luz dos princípios da razoabilidade e proporcionalidade, quando da quantificação do valor da indenização por dano moral.

Por derradeiro, é de se observar que o entendimento majoritário, tanto doutrinário como jurisprudencial, no que concerne a ao tema ora em análise, apontam pela prevalência no sistema de que a tarifação do dano moral nas relações de trabalho estabelecido no $§ 1^{\circ}$, I a IV, do art. 223-G da CLT, é de caráter inconstitucional, por determinar limite a fixação da indenização por dano moral à pessoa ofendida, o que pode impedir a reparação integral do dano. Sua prevalência, portanto, ofende os princípios da dignidade da pessoa humana, a isonomia e da reparação integral dos danos esculpidos na Constituição Federal.

\section{CONSIDERAÇÕES FINAIS}

A Lei $n^{\circ}$. 13.467/17, também chamada de lei da Reforma Trabalhista, trouxe significativas alterações ao Direito Laboral, em especial, no que se refere ao art. 223-G, $\S 1^{\text {o }}$ da CLT, objeto deste estudo, vez que passou a prever a tarifação do dano extrapatrimonial, com a estipulação de tabelamento das indenizações por danos morais, tendo como parametrização, o salário recebido pela vítima.

O dano moral imaterial ou também chamado de dano extrapatrimonial, impõe que seja observada a dignidade humana, sendo ela, considerada como um atributo da personalidade humana, daí, afetar o bem personalíssimo e atingir, portanto, a esfera íntima de cada indivíduo.

No que tange à indagação que norteou esta pesquisa, qual seja, a fixação do quantum indenizatório, quando da reparação de dano de natureza extrapatrimonial na relação de trabalho. A perquirição se assenta, no sentido de discutir se o parâmetro da ofensa como de natureza gravíssima, ao prever limitação em até 50 vezes o valor do último salário contratual do ofendido, contempla ou não todos os casos nele enquadrados? É possível concluir que a indenização de dano extrapatrimonial no âmbito das relações de trabalho, quando da parametrização do quantum indenizatório à valores máximos a título de reparação, viola o princípio da igualdade e da reparação integral do dano, nos termos do artigo $5^{\circ}$, caput e incisos V e X e $7^{\circ}$, XXVIII, da Constituição Federal de 1988. Assim como, tal parametrização, pode também ofender por si, o princípio solar da dignidade da pessoa humana, conforme $\operatorname{art.} 1^{\circ}$, III, da Carta Magna, dada sua insuficiência em contemplar os inúmeros casos passíveis de 
reparação por dados morais extrapatrimoniais, em havendo tratamento distinto para aqueles que possuem maior remuneração, quando da fixação do quantum indenizatório.

A fixação de tetos, conforme discriminado pelo legislador, é entendido como fator limitar à atuação do magistrado, quando da interpretação do caso a ele submetido, o que pode lhe impossibilitar ter como norte, os princípios da razoabilidade e proporcionalidade, para fins de fixação do valor da indenização por dano moral. Isso ao se compreender que o dano extrapatrimonial é aferido à partir do espectro da ofensa sofrida, não devendo ter, portanto, vinculação ao salário do trabalhador/ofendido, mas sim, a gravidade da lesão por ele suportada.

A matéria, ao ser submetida à apreciação dos tribunais, por meio de incidente de arguição de inconstitucionalidade, quanto da limitação imposta para o arbitramento dos danos extrapatrimoniais. Inúmeros Tribunais Regionais do Trabalho, já tem decidido pela inconstitucionalidade do art. 223-G, $\S 1^{\circ}$, I A IV, da CLT, diante da incompatibilidade material com a Constituição Federal. Essas decisões, foram sumuladas, para fins de declarar a inconstitucionalidade do citado artigo, vez ser ele, materialmente incompatível com os princípios constitucionais da dignidade da pessoa humana, da isonomia e da reparação integral do dano. Além de não atender ao caráter pedagógico de reparação do dano, ofendendo as disposições constitucionais dispostas no art. $5^{\circ}$, V e X, da Carta Magna.

Por fim, resta clarificado que, da analisar do disposto no art. $223-\mathrm{G}, \S 1^{\circ}$, da CLT, que trata da tarifação do dano extrapatrimonial, à luz das decisões jurisprudenciais que enfrentaram o tema, é tal dispositivo considerado inconstitucional, tendo sua declaração de inconstitucionalidade, apontado no sentido de que existem na norma, caminhos mais equânimes para fins de equalização mais justas quanto às decisões que enfrentam a fixação do dano extrapatrimonial, do que aquela trazida no bojo da Reforma Trabalhista.

\section{REFERÊNCIAS}

BRASIL. Lei $n^{o}$. 10.406, de 10 de janeiro de 2002. Institui o Código Civil. Disponível em <http://www.planalto.gov.br/ccivil_03/leis/2002/L10406compilada.htm>. Acesso em: $20 \mathrm{de}$ outubro de 2020.

BRASIL. Decreto-Lei $n^{o}$. 5.452, de 01 de maio de 1943. Aprova a Consolidação das Leis do Trabalho. Disponível em: <http://www.planalto.gov.br/ccivil_03/Decreto-

Lei/Del5452.htm>. Acesso em 20 de outubro de 2020.

BRASIL. Constituição da República Federativa do Brasil de 1988. Promulgada em 05 de outubro de $1988 . \quad$ Disponível em: 
http://www.planalto.gov.br/ccivil_03/constituicao/constituicao.htm> Acesso em 20 de outubro de 2020.

BRASIL. Lei n. 9.029/95, $4^{\circ}$, de 13 de abril de 1995. Proíbe a exigência de atestados de gravidez e esterilização, e outras práticas discriminatórias, para efeitos admissionais ou de permanência da relação jurídica de trabalho, e dá outras providências. Disponível em:< http://www.planalto.gov.br/ccivil_03/leis/19029.htm>. Acesso em: 28 de outubro de 2020.

CAIRO JÚNIOR, José. Curso de Direito do Trabalho. 11. ed. Salvador: JusPodivm, 2015.

GARCIA, Gustavo Filipe Barbosa. Curso de Direito do Trabalho. 8 ed. Rio de Janeiro:

Forense, 2015.

GONÇALVES, Carlos Roberto. Responsabilidade Civil. 18. ed. São Paulo: Saraiva, 2019.

JUSTIÇA DO TRABALHO. TRIBUNAL REGIONAL DO TRABALHO DA $23^{\text {a }}$ REGIÃO. PROCESSO $n^{\circ}$ 0000239-76.2019.5.23.0000. RELATOR: DESEMBARGADOR TARCÍSIO VALENTE. Disponível

em:

$<$ https://portal.trt23.jus.br/portal/sites/portal/files/groups/stp/trt_arginc_000239-

76.2019.5.23.0000.pdf>. Acesso em 08 de novembro de 2020

JUSTIÇA DO TRABALHO. TRIBUNAL REGIONAL DO TRABALHO DA $23^{\mathrm{a}}$ REGIÃO. SÚMULA 48.Disponível em:< https://portal.trt23.jus.br/portal/sumulas/s\%C3\%BAmulan\%C2\%BA-48>. Acesso em 08 de novembro de 2020.

JUSTIÇA DO TRABALHO. TRIBUNAL REGIONAL DO TRABALHO DA $3^{\text {a }}$ REGIÃO. PROCESSO $n^{o}$ 0011521-69.2019.5.03.0000. RELATOR: DESEMBARGADOR SEBASTIÃO GERALDO DE OLIVEIRA. Disponível em:< https://portal.trt3.jus.br/internet/jurisprudencia/incidentes-suscitados-irdr-iac-arginc-iuj-trtmg/downloads/arginic/Acordao_merito_20_7_20.pdf>. Acesso em 08 de novembro de 2020.

JUSTIÇA DO TRABALHO. TRIBUNAL REGIONAL DO TRABALHO DA $3^{\mathrm{a}}$ REGIÃO. PROCESSO $N .{ }^{\circ}$ 0010510-06.2019.5.03.0129. DESEMBARGADOR VITOR SALINO DE MOURA EÇA. Disponível em:< https://juris.trt3.jus.br/juris/detalhe.htm? conversationId=661>. Acesso em 05 de novembro de 2020.

JUSTIÇA DO TRABALHO. TRIBUNAL REGIONAL DO TRABALHO DA $8^{\mathrm{a}}$ REGIÃO. PROCESSO $n^{\circ}$ 0000514-08.2020.5.08.0000. RELATOR: DESEMBARGADOR GABRIEL VELLOSO. Disponível em: <https://www.trt8.jus.br/sites/portal/files/roles/assessoria-decomunicacao/acordao_arginc_0000514-08.2020.5.08.000.pdf>. Acesso em 08 de novembro de 2020 .

MARTINEZ, Luciano. Curso de Direito do Trabalho. 11. ed. Saraiva, 2020.

MARTINS, Sérgio Pinto. Direito do Trabalho. 30. ed. São Paulo: Atlas, 2015.

MARTINS, Thiago Penido; REIS, Pedro Augusto Gomes Santiago. A Revolução Francesa de 1789 e a teoria da separação dos poderes como marco para o início da constitucionalização do direito francês instrumentalizado pela constituição de 1791. Organização Comitê Científico, 2019. Disponível em: <file:///C:/Users/User/Downloads/A_REVOLUCAO_FRANCESA_DE_1789_E_A_TEORI A_DA_SEPARAC\%20(2).pdf>. Acesso em 23 de outubro de 2020. 
NASCIMENTO, Amauri Mascaro. Curso de direito do trabalho: história e teoria geral do direito do trabalho: relações individuais e coletivas do trabalho. 19. ed. São Paulo: Saraiva, 2004.

ROMAR, Carla Teresa Martins. Direito do Trabalho. Coordenador Pedro Lenza. 4. ed. São Paulo. Saraiva, 2017.

TREMEL, Rosangela; CALCINI, Ricardo. Reforma Trabalhista. Campina Grande: EDUEPB, 2018. 